\title{
Demokrasi Sebagai Pembangunan Kesehatan Masyarakat
}

\author{
Etha Oktavia Puspita Dewi \\ Institut Ilmu Kesehatan STRADA Indonesia \\ oktavetha@gmail.com
}

\begin{abstract}
Abstrak
Demokrasi yang bebas dan adil tampaknya penting untuk meningkatkan kesehatan orang dewasa dan hasil penyakit yang tidak menular, serta kemungkinan besar dengan meningkatkan akuntabilitas dan daya tanggap pemerintah. Kehidupan demokrasi ternyata berhubungan dengan penanganan penyakit menjadi lebih baik, bahwa demokrasi dapat memberikan prioritas lebih tinggi untuk investasi perawatan kesehatan. Studi menunjukkan bahwa pemerintahan yang demokratis dan promosinya, bersama dengan langkah-langkah akuntabilitas pemerintah lainnya, dapat lebih meningkatkan upaya untuk meningkatkan kesehatan populasi. Hasil penelitian ini menunjukkan bahwa demokrasi dan kesehatan rakyat semakin tak terpisahkan. Kardiovaskular, tuberkulosis, cedera transportasi, dan beberapa penyakit tidak menular bertanggungjawab atas $25 \%$ dari total kematian dan kecacatan pada orang yang berusia kurang dari 70 tahun di negara berpenghasilan rendah dan menengah. Selama 20 tahun terakhir, demokrasi mengurangi angka kematian di negara-negara berkembang dari tuberkulosis dan kardiovaskular serta beberapa jenis penyakit tidak menular antara 8-10 persen.
\end{abstract}

\section{Kata Kunci : Demokrasi, Pembangunan, Kesehatan Masyarakat}

\section{Latar Belakang}

Hasil penelitian terbaru dari Stanford University School of Medicine (Stanford Medicine) yang berbasis di California, Amerika Serikat, menunjukkan bahwa sistem demokrasi telah berperan dalam meningkatkan kesehatan global, terutama pada penyebab kematian orang dewasa, seperti penyakit tidak menular, tuberkulosis, kardiovaskular, cedera transportasi, bahkan HIV, dan lain-lain.

Proses demokrasi, khususnya pemilihan umum yang bebas dan adil, dapat menjadi katalisator penting untuk meningkatkan kesehatan populasi manusia. Hasil penelitian ini menunjukkan bahwa demokrasi dan kesehatan rakyat semakin tak terpisahkan. 
Kardiovaskular, tuberkulosis, cedera transportasi, dan beberapa penyakit tidak menular bertanggungjawab atas $25 \%$ dari total kematian dan kecacatan pada orang yang berusia kurang dari 70 tahun di negara berpenghasilan rendah dan menengah. Selama 20 tahun terakhir, demokrasi mengurangi angka kematian di negara-negara berkembang dari tuberkulosis dan kardiovaskular serta beberapa jenis penyakit tidak menular antara 8-10 persen.

Pembangunan kesehatan adalah bagian dari pembangunan nasional yang bertujuan meningkatkan kesadaran, kemauan dan kemampuan hidup sehat bagi setiap orang agar terwujud derajat kesehatan masyarakat yang setinggi-tingginya. Pembangunan kesehatan tersebut merupakan upaya seluruh potensi bangsa Indonesia, baik masyarakat, swasta maupun pemerintah. Untuk menjamin tercapainya tujuan pembangunan kesehatan, diperlukan dukungan dari Sistem Kesehatan Nasional (SKN). SKN berperan besar sebagai acuan dalam penyusunan UU tentang Kesehatan, juga dalam penyusunan berbagai kebijakan, pedoman dan arah pelaksanaan pembangunan kesehatan. Dalam SKN terdapat subsistem upaya kesehatan terdiri dari Upaya Kesehatan Masyarakat (UKM) dan Upaya Kesehatan Perorangan (UKP). Penyelenggaraan pelayanan kesehaan di rumah sakit termasuk dalam UKP Strata kedua dan ketiga yaitu yang mendayagunakan ilmu pengetahuan dan teknologi kedokteran spesialistik dan subspesialistik.

Kesehatan Masyarakat Kesehatan masyarakat memiliki peran penting dalam upaya peningkatan kualitas sumber daya manusia, penanggulangan kemiskinan dan pembangunan ekonomi. Indeks Pembangunan Manusia meletakkan kesehatan adalah salah satu komponen utama pengukuran selain pendidikan dan pendapatan. Kondisi umum kesehatan Indonesia dipengaruhi oleh faktor lingkungan, perilaku, dan pelayanan kesehatan. Sementara itu pelayanan kesehatan terdiri dari beberapa komponen antara lain ketersediaan dan mutu fasilitas pelayanan kesehatan, obat dan perbekalan kesehatan, tenaga kesehatan, pembiayaan dan manajemen kesehatan. Fasilitas pelayanan kesehatan dasar, yaitu Puskesmas yang diperkuat dengan Puskesmas Pembantu dan Puskesmas Keliling, telah didirikan di hampir seluruh wilayah Indonesia, namun pemerataan dan keterjangkauan pelayanan kesehatan masih menjadi kendala.

Demokrasi yang bebas dan adil tampaknya penting untuk meningkatkan kesehatan orang dewasa dan hasil penyakit yang tidak menular, serta kemungkinan besar dengan meningkatkan akuntabilitas dan daya tanggap pemerintah. Kehidupan demokrasi ternyata berhubungan dengan penanganan penyakit menjadi lebih baik, bahwa demokrasi dapat memberikan prioritas lebih tinggi untuk investasi perawatan kesehatan. Studi menunjukkan 
bahwa pemerintahan yang demokratis dan promosinya, bersama dengan langkah-langkah akuntabilitas pemerintah lainnya, dapat lebih meningkatkan upaya untuk meningkatkan kesehatan populasi

\section{Kasus/Masalah}

Dari pembahasan latar belakang di atas maka dapat merumuskan beberapa rumusan masalah/kasus, seperti:

1. Bagaimana Demokrasi dapat meningkatkan pembangunan kesehatan masyarakat?

2. Apakah peran Demokrasi dalam kesehatan masyarakat?

3. Bagaimanakah peran mahasiswa atau masyarakat dalam demokrasi kesehatan masyarakat?

\section{Tinjauan Pustaka}

\subsection{Teori Penelitian/ Artikel}

Artikel ini bersumber dari beberapa jurnal dan publikasi online yang dirangkum dalam beberapa kalimat. Dengan mengambil tema demokrasi sebagai pembangunan kesehatan masyarakat yang berbasis artikel online penelitian terbaru dari Stanford University School of Medicine (Stanford Medicine) yang berbasis di California, Amerika Serikat, menunjukkan bahwa sistem demokrasi telah berperan dalam meningkatkan kesehatan global, terutama pada penyebab kematian orang dewasa, seperti penyakit tidak menular, tuberkulosis, kardiovaskular, cedera transportasi, bahkan HIV, dan lain-lain.

Demokrasi telah diteliti dapat meningkatkan pembangunan kesehatan masyarakat di Negara Negara berkembang khususnya di Indonesia. Dengan memanfaatkan salah satu kegiatan demokrasi yaitu pemilihan umum secara adil dan terbuka dengan melibatkan unsur kesehatan pada masyarakat maka dapat meningkatkan pembangunan health. Sebagai bentuk health promotion demokrasi dipandang mampu menjadi wadah peningkatan kesehatan.

Teori yang telah dibahas sudah diteliti dan dijalankan diberbagai Negara. Demokrasi kesehatan sebagai pembangunan adalah kata kunci untuk memggerakan masyarakat khususnya peningkatan derajat kesehatan. 


\subsection{Demokrasi}

Demokrasi adalah bentuk pemerintahan di mana semua warga negaranya memiliki hak yang sama pengambilan keputusan yang dapat mengubah hidup mereka. Demokrasi mengizinkan warga negara berpartisipasi-baik secara langsung atau melalui perwakilandalam perumusan, pengembangan, dan pembuatan hukum. Demokrasi mencakup kondisi sosial, ekonomi, dan budaya yang memungkinkan adanya praktik kebebasan politik secara bebas dan setara. Demokrasi juga merupakan seperangkat gagasan dan prinsip tentang kebebasan beserta praktik dan prosedurnya. Demokrasi mengandung makna penghargaan terhadap harkat dan martabat manusia.

Ada beberapa jenis demokrasi, tetapi hanya ada dua bentuk dasar. Keduanya menjelaskan cara seluruh rakyat menjalankan keinginannya. Bentuk demokrasi yang pertama adalah demokrasi langsung, yaitu semua warga negara berpartisipasi langsung dan aktif dalam pengambilan keputusan pemerintahan. Di kebanyakan negara demokrasi modern, seluruh rakyat masih merupakan satu kekuasaan berdaulat namun kekuasaan politiknya dijalankan secara tidak langsung melalui perwakilan; ini disebut demokrasi perwakilan.

\subsection{Pembangunan Kesehatan Masyarakat}

Pembangunan kesehatan merupakan salah satu upaya pembangunan nasional yang diarahkan guna mencapai kesadaran, kemauan dan kemampuan untuk hidup sehat bagi setiap penduduk agar dapat mewujudkan derajad kesehatan yang optimal. Kesehatan optimal yaitu dimana keadaan sejahtera dari badan, jiwa dan sosial yang memungkinkan setiap orang hidup produktif secara sosial dan ekonomis (Bina Depnakes, 2003 ).

Dalam Sistem Kesehatan Nasional pembangunan kesehatan merupakan salah satu upaya Pembangunan Nasional yang diarahkan dalam rangka tercapainya kesadaran, kemauan dan kemampuan untuk hidup sehat bagi setiap penduduk agar dapat mewujudkan derajat kesehatan yang optimal.Untuk mencapai tujuan tersebut dibutuhkan upaya pengembangan pelayanan kesehatan di berbagai jenis dan jenjang pelayanan, sehingga terwujud pelayanan kesehatan yang efisien, bermutu dan terjangkau. Upaya tersebut perlu didukung dengan komitmen serta dilaksanakan dengan semangat pemberdayaan yang tinggi dan diprioritaskan kepada upaya promosi, pencegahan dan pengendalian penyakit serta penyembuhan dan pemulihan(Kenmenkes RI,2011).

Pembangunan kesehatan masyarakat sangat erat kaitannya dengan ketersediaan sarana dan prasarana penunjang kesehatan itu sendiri. Pemenuhan hak atas kesehatan bagi masyarakat dilakukan dengan upaya pembangunan kesehatan yang menyeluruh dan 
berkelanjutan. Pembangunan kesehatan masyarakat sangat erat kaitannya dengan ketersediaan sarana dan prasarana penunjang kesehatan itu sendiri.

\subsection{Peran Demokrasi Dalam Kesehatan Masyarakat}

Kesehatan sebagai komoditas merupakan bagian tidak terpisahkan dari perkembangan sistem demokrasi di Indonesia. Demokrasi berasal dari bahasa Yunani: demos yang berarti rakyat dan kratos yang berarti pemerintahan. Demokrasi (liberal) menurut Georg Sorensen adalah liberal dahulu (bertujuan untuk membatasi kekuasaan negara atas masyarakat sipil dan demokrasi kemudian (bertujuan untuk meciptakan struktur yang akan mengamankan mandat rakyat untuk para pemegang kekuasaan negara). Banyak definisi-definisi lain tentang demokrasi, termasuk berbagai jenis demokrasi yang berkembang sejak kelahirannya di Yunani. Proses demokrasi dan demokratisasi membawa dampak besar pada pelayanan kesehatan di Indonesia. Proses pembangunan di Indonesia sebagaimana juga terjadi dengan pembangunan di negara-negara dunia ketiga lainnya, dalam wacana pembangunan dapat dipahami dari beberapa perspektif. Pada dasarnya pembangunan yang saat ini berlangsung dipandang sebagai suatu proses perkembangan kapitalisme dalam bentuk dan mekanisme yang beragam. Pertanyaan krusial yang masih relevan dipertanyakan, apakah integrasi dunia ketiga dalam suatu dunia kapitalis global akan memberikan kesempatan pada negara-negara dunia ketiga untuk berkembang ataukah justru akan melembagakan keterbelakangannya.

Demokrasi yang bebas dan adil tampaknya penting untuk meningkatkan kesehatan orang dewasa dan hasil penyakit yang tidak menular, serta kemungkinan besar dengan meningkatkan akuntabilitas dan daya tanggap pemerintah. Kehidupan demokrasi ternyata berhubungan dengan penanganan penyakit menjadi lebih baik, bahwa demokrasi dapat memberikan prioritas lebih tinggi untuk investasi perawatan kesehatan. Studi menunjukkan bahwa pemerintahan yang demokratis dan promosinya, bersama dengan langkah-langkah akuntabilitas pemerintah lainnya, dapat lebih meningkatkan upaya untuk meningkatkan kesehatan populasi 


\section{Pembahasan}

\subsection{Peran Mahasiswa dan Masyarakat dalam Membangun Demokrasi Kesehatan}

Demokrasi ialah bentuk pemerintahan yang setiap individu memiliki kesetaraan hak dalam mengambil keputusan, dan dapat memengaruhi kehidupan individu tersebut. Demokrasi yang sehat kini mulai luntur di berbagai lingkup sosial, termasuk lingkungan mahasiswa kampus. Lalu bagaimana peran mahasiswa dalam membangun serta mempertahankan demokrasi kesehatan? Pandemi mengakibatkan demokrasi dalam pemilu saat ini memiliki euforia yang berbeda serta antusiasme dari masyarakat yang berbeda, terkhusus demokrasi yang tidak memperhatikan aspek amanan dan kesehatan. dengan sistem online banyak sekali perbedaan mulai dari teknis pemilihan, euforia, serta kegiatannya menjadi sulit untuk menyeluruh. Dalam menciptakan demokrasi sehat dilihat dari calon penerus organisasi khususnya hima kesehatan, untuk dapat membawa gagasan dan tujuan yang baik, visi misi yang jelas, mempunyai orientasi yang baik serta visioner.

Mahasiswa harus sadar dan bisa menanamkan bahwa demokrasi dapat menjadi wadah bagi kesehatan adalah bukan tindakan yang selalu buruk. Kesehatan adalah kondisi kesejahteraan fisik, mental, dan sosial yang lengkap dan bukan sekadar tidak adanya penyakit atau kelemahan. Pemahaman tentang kesehatan telah bergeser seiring dengan waktu. Urgensi untuk demokrasi sendiri yaitu kebebasan. Antara lain ialah kebebasan masyarakat dalam berpendapat, kebebasan media-media, kebebasan penentuan sikap dari masyarakat dalam menentukan haknya. Kemudian, demokrasi juga bebas dalam berekspresi, namun harus sesuai dengan culture bangsa, dan Pancasila serta UUD 1945.

Demokrasi kesehatan yaitu dapat menampung aspirasi dan kepentingan masyarakat dalam kesehatan. Dan memperhatikan pertimbangan kesehatan masyarakat. Mahasiswa dan masyarakat sipil diharapkan memiliki prinsip sendiri saat melakukan demokrasi kesehatan. Indonesia merupakan negara demokrasi, maka yang menjalankan suatu negara itu tidak hanya kepemimpinan pemerintah saja, tetapi rakyat juga ikut andil dalam menggerakkan suatu negara. Sehingga, rakyat juga harus memilik power dalam menggerakkan demokrasi. 


\subsection{Demokrasi Kesehatan Masyarakat}

Riset terhadap 170 negara menunjukkan dampak sistem demokrasi terhadap kesehatan populasi untuk pertama kalinya. Salah satu cara terbaik mengukur peran demokrasi dalam kesehatan masyarakat adalah dengan mengamati penyebab kematian orang dewasa di suatu negara. Termasuk di dalamnya penyakit tidak menular, HIV, penyakit kardiovaskular, dan kecelakaan transportasi.

Lembaga dan proses demokrasi, khususnya pemilihan umum yang bebas dan adil, bisa menjadi katalisator penting untuk meningkatkan kesehatan populasi, dengan perolehan kesehatan terbesar yang mungkin untuk penyakit kardiovaskular dan penyakit tidak menular lain. Riset ini memberi pemahaman baru tentang bagaimana tata kelola dan kesehatan menginformasikan debat kebijakan kesehatan global, terutama ketika pendanaan kesehatan global menurun.

Menurut para peneliti, meningkatnya pengalaman demokrasi selama 20 tahun terakhir telah mengurangi angka kematian di negara-negara ini. Tepatnya antara 8 dan 10 persen, baik karena penyakit kardiovaskular, penyakit tidak menular lain, dan tuberkulosis. Pemilihan umum yang bebas dan adil tampaknya penting untuk meningkatkan kesehatan orang dewasa dan penyakit yang tidak menular, kemungkinan besar dengan meningkatkan akuntabilitas dan daya tanggap pemerintah.

Indeks demokrasi Indonesia (IDI) secara nasional dari tahun 2009 hingga tahun 2015 mencapai angka 72,82 dalam skala 0 sampai 100. Capaian ini masih berada pada kategori "sedang". Klasifikasi tingkat demokrasi dikelompokkan menjadi tiga kategori: yakni "baik" (indeks > 80), "sedang” (indeks $60-80$ ), dan "buruk" (indeks $<60$ ).

\subsection{Perkembangan demokrasi di Indonesia}

Kembali ke riset baru, analisis mengungkap demokrasi berkaitan dengan angka penyakit tidak menular yang lebih baik. Para peneliti berteori, demokrasi mungkin memberikan prioritas lebih tinggi untuk investasi perawatan kesehatan. Pemerintah demokratis belum menjadi kekuatan pendorong dalam kesehatan global. Banyak negara dengan peningkatan terbesar dalam harapan hidup dan kematian anak selama 15 tahun terakhir adalah otokrasi pemilu yang mencapai keberhasilan kesehatan mereka dengan kontribusi besar bantuan asing.

Para ahli mencatat, Ethiopia, Myanmar, Rwanda dan Uganda memperpanjang harapan hidup rakyatnya 10 tahun atau lebih antara tahun 1996 hingga 2016. Sementara negara- 
negara ini termasuk yang paling tidak demokratis di dunia, mereka adalah penerima utama bantuan asing untuk kesehatan. Studi ini menunjukkan pemerintahan yang demokratis, bersama dengan langkah-langkah akuntabilitas pemerintah lain, bisa lebih meningkatkan upaya perbaikan kesehatan populasi. Bersikap sebaliknya sama dengan meyakini bahwa solusi untuk jalan dan infrastruktur negara yang hancur hanyalah sebuah skema teknis dan material yang lebih murah.

\section{Kesimpulan}

Studi ini menunjukkan pemerintahan yang demokratis, bersama dengan langkahlangkah akuntabilitas pemerintah lain, bisa lebih meningkatkan upaya perbaikan kesehatan populasi. Demokrasi yang bebas dan adil tampaknya penting untuk meningkatkan kesehatan orang dewasa dan hasil penyakit yang tidak menular, serta kemungkinan besar dengan meningkatkan akuntabilitas dan daya tanggap pemerintah. Kehidupan demokrasi ternyata berhubungan dengan penanganan penyakit menjadi lebih baik, bahwa demokrasi dapat memberikan prioritas lebih tinggi untuk investasi perawatan kesehatan. Artikel ini membahasa mengenai demokrasi yang berperan dalam pembangunan kesehatan masyarakat. 


\section{Daftar Pustaka}

Timon, A. (2020). Tanggung Jawab Negara Hukum Demokrasi dalam Penyelenggaraan Pelayanan Kesehatan. Soumatera Law Review, 3(1), 18-29.

Widhyharto, D. S. Demokrasi dan Komodifikasi Perlindungan Kesehatan Perempuan. Jurnal Pemikiran Sosiologi, 1(1), 44-57.

Ayuningtyas, D. (2009). Politik Pembangunan dan Kebijakan Privatisasi Pelayanan Kesehatan. Jurnal Manajemen Pelayanan Kesehatan, 12(03), 22320.

Sodik, M. A., Suprapto, S. I., \& Pangesti, D. (2013). Faktor-Faktor Yang Berhubungan Dengan Pelaksanaan Pelayanan Prima Pegawai Di Rsui Orpeha Tulungagung. STRADA Jurnal Ilmiah Kesehatan, 2(1), 24-32.

Sodik, M. A., \& Nzilibili, S. M. M. (2017). The Role Of Health Promotion And Family Support With Attitude Of Couples Childbearing Age In Following Family Planning Program In Health. Journal of Global Research in Public Health, 2(2), 82-89.

Sodik, M. A. (2016). Leprosy Patients in public perception: A qualitative study of patient confidence (dis) in the Community. J Global Res Public Health, 1(2), 99-106. 